\title{
O papel da aprendizagem no processo de internacionalização: um estudo de caso na Acumuladores Moura S/A
}

\author{
The role of learning in the internationalization process: a case study at \\ Acumuladores Moura S/A
}

\author{
Anderson Clayton Oliveira Silva ${ }^{1}$ \\ Viviane Santos Salazar ${ }^{2}$
}

\begin{abstract}
Resumo
O objetivo deste estudo é investigar o papel da aprendizagem no processo de internacionalização de uma grande empresa localizada em um país emergente. Para alcançá-lo, foram utilizadas abordagens comportamentais: Teoria de Uppsala, Teoria de Redes e Teoria do empreendedorismo internacional. Ademais, discute-se também a relação entre a aprendizagem e a internacionalização. Trata-se de uma pesquisa de natureza qualitativa, com uma abordagem de estudo de caso. A coleta de dados foi realizada por meio de entrevistas semiestruturadas, pesquisa documental e investigação bibliográfica. Além disso, para a análise dos dados, utilizou-se o método da comparação constante. Os resultados obtidos indicaram que a busca pela aprendizagem nas fases iniciais da empresa contribuiu para realização de parcerias e para o desenvolvimento da organização. Outro achado interessante refere-se ao fato de a empresa iniciar relações com países psiquicamente distantes por conta do desejo do fundador em aprender nos maiores mercados do mundo. Por fim, é possível destacar a influência da aprendizagem experiencial na mudança estratégica internacional da empresa.
\end{abstract}

Palavras-chaves: Aprendizagem. Internacionalização. Abordagens Comportamentais. Estudo de Caso. Método da Comparação Constante.

\begin{abstract}
The purpose of this study is to investigate the role of learning in the process of internationalization of a large company located in an emerging country. In order to achieve this goal, behavioral approaches are used: Uppsala Theory, Networks Theory and Theory of International Entrepreneurship. It also addresses the relationship between learning and internationalization. This is a qualitative research with a case study approach. Data collection was done through semi-structured interviews, documentary research and bibliographic research. Besides that, the data analysis was performed using the constant comparison method. The results indicated that the search for learning in the early stages of the company contributed to the realization of partnerships and to the development of the organization. Another interesting finding refers to the fact that the company initiates relations with countries psychically distant because of the founder's desire to learn in the largest markets in the world. Finally, it is also possible to highlight the influence of experiential learning on the international strategic change of the company.
\end{abstract}

Keywords: Learning. Internationalization. Behavioral Approaches. Case Study. Constant Comparison Method.

\section{Introdução}

As empresas não se limitam mais a buscar oportunidades apenas dentro das suas fronteiras nacionais (CAVUSGIL; KNIGHT; RIESENBER, 2016), aumentando, assim, o fluxo de produtos e serviços entre os

Mestre em Administração pelo Programa de Pós-graduação em Administração da Universidade Federal de Pernambuco (PROPAD/UFPE). Especialista em Administração Pública e Gerência de Cidades pela Uninter (2014). Graduado em Administração de Empresas pela Universidade de Pernambuco (2013) e graduado em Jornalismo pela Universidade Federal de Pernambuco (2012). Atualmente é Coordenador de Gestão de Pessoas do Instituto Federal de Pernambuco - Campus Cabo de Santo Agostinho. Brasil. Afiliação: Universidade Federal de Pernambuco. Lattes: http://buscatextual.cnpq.br/buscatextual/visualizacv.do?id=K4468608D6 Email: andersoncosilva@gmail.com

2 Professora Adjunto I do Departamento de Hotelaria e Turismo da Universidade Federal de Pernambuco. É bacharel em Hotelaria pela Universidade Federal de Pernambuco (2000), e em Administração de Empresas pela Universidade de Pernambuco (2003). Mestre e Doutora em Administração pela Universidade Federal de Pernambuco. Tem como áreas de interesse de pesquisa Estratégia Empresarial, Marketing de Serviços e Comportamento do Consumidor com foco em empresas de hospitalidade. Brasil. Afiliação: Universidade Federal de Pernambuco. Lattes: http://buscatextual.cnpq.br/buscatextual/visualizacv.do?id=K4734168T4 Email: viviane_salazar@yahoo.com.br 
diversos países. Em 1960, o comércio global era de US\$ 100 bilhões por ano. Quase 60 anos depois, as exportações mundiais chegam a US\$ 18 trilhões por ano (CAVUSGIL; KNIGHT; RIESENBER, 2016).

Esse aumento pode ser atribuído a alguns fatores, como: o crescimento de mercados emergentes nas últimas três décadas; o desenvolvimento de algumas economias, como os EUA e a União Europeia, que passaram a consumir produtos de baixo custo vindos da China, Índia e México; os avanços na informação e na troca de tecnologias; e a queda das barreiras e liberalização dos mercados (CAVUSGIL; KNIGHT; RIESENBER, 2016).

Diante desses fatos e devido ao pequeno número de estudos nos países emergentes (KEUPP; GASSMANN, 2009, SERVANTIE et al., 2016), torna-se relevante pesquisar o processo de internacionalização de uma empresa de grande porte instalada num desses países. Ademais, há poucas pesquisas sobre aprendizagem organizacional na literatura das teorias de internacionalização. Observa-se, por exemplo, que apenas algumas teorias debruçam-se sobre os aspectos comportamentais que influenciam, ou que estão presentes, no contexto da internacionalização, como a Teoria de Uppsala, a Teoria de redes e a Teoria do empreendedorismo internacional (El).

Outrossim, também é importante entender a internacionalização como um processo, ou seja, uma sequência de eventos que descreve como as coisas mudam ao longo do tempo (VAN DE VEN, 1992). Nesse sentido, alguns autores defendem que a pesquisa longitudinal possibilita uma melhor compreensão das organizações (JOHANSON; VAHLNE, 1977, 2009; LEITE; MORAES, 2014).

Diante desse contexto, surge a pergunta de pesquisa: Qual a influência da aprendizagem no processo de internacionalização de uma empresa de grande porte? Com isso, o objetivo é investigar o papel da aprendizagem no processo de internacionalização em uma grande empresa localizada em um país emergente.

O lócus da pesquisa foi a empresa Acumuladores Moura, localizada no município de Belo Jardim, agreste de Pernambuco. Entre os dez maiores fabricantes de baterias automotivas do país, a Moura é a única que possui sua sede na região Nordeste, as demais estão instaladas nas regiões Sul e Sudeste (PEREIRA; BÁNKUTI, 2016). No ano de 2015, as vendas líquidas da empresa foram maiores do que US $\$ 200$ milhões (EXAME, 2017). Nessa perspectiva, percebe-se que a atividade industrial da empresa é importante para a região e contribui para que o Nordeste transforme-se num "centro de expansão" (PEREIRA JÚNIOR, 2015).

Além da sua importância para a região, a Moura foi escolhida como estudo de caso a partir de alguns critérios específicos. Ao escolher uma empresa de grande porte, localizada num país emergente, com 60 anos de atuação no mercado, cujas primeiras exportações aconteceram 25 anos depois da sua fundação, objetivava-se estudar o fenômeno do empreendedorismo internacional a partir de uma perspectiva diferente, já que normalmente, os objetos de estudo no El são pequenas e médias empresas, localizadas em regiões desenvolvidas, com um rápido processo de internacionalização.

\section{Fundamentação Teórica}

Esta seção está divida em duas partes. Na primeira, são apresentadas as teorias comportamentais da área de internacionalização que são utilizadas para a construção desta pesquisa. Em um segundo momento, é discutida a relação entre aprendizagem e internacionalização.

\subsection{Abordagens comportamentais da internacionalização}

Os movimentos de internacionalização de empresas ao redor do mundo podem ser estudados basicamente por duas perspectivas: uma perspectiva econômica e outra comportamental (CARNEIRO; DIB, 2007).

Dentre as teorias econômicas que objetivam explicar a internacionalização das empresas, destacam-se: (i) a Teoria do ciclo de vida do produto (VERNON, 1966); (ii) o paradigma eclético (DUNNING, 1980); (iii) e o modelo Diamante (PORTER, 1999). Entre as teorias classificadas como mais comportamentais, denominadas também de "modelos de estágios", destacam-se (i) o modelo de Uppsala (JOHANSON; VAHLNE, 1977), que afirma que a internacionalização das empresas ocorre de maneira gradual e a velocidade e os locais 
escolhidos como alvos dependem da distância psíquica entre os países; (ii) a Teoria das Redes (JOHANSON; MATTSON, 1988; FORSGREN, 2008), que argumenta que as redes de relacionamento desempenham um papel importante na internacionalização das empresas; e (iii) a Teoria do empreendedorismo internacional (MCDOUGALL, 1989), também chamado El, que defende que as empresas nacionais procuram explorar e desenvolver oportunidades em outros países com o intuito de obter vantagem competitiva.

Assim sendo, o foco desse estudo está voltado para essas três teorias comportamentais. O modelo de Uppsala, em sua versão original (JOHANSON; VAHLNE, 1977), argumenta que a internacionalização ocorre por meio de um processo incremental, em que o comprometimento de recursos no mercado-alvo cresce gradativamente. À medida que o tempo passa, que a aprendizagem aumenta e que a distância psíquica diminui, a internacionalização se intensifica cada vez mais. Distância psíquica refere-se às diferenças culturais, políticas, educacionais, de idioma, de modelos mentais de pensamento, de tradições, entre o país de origem e o país estrangeiro (JOHANSON; VALHNE, 1977).

Johanson e Vahlne (1977) citam a existência de quatro etapas: (i) não há atividades regulares de exportação; (ii) exportação por meio de agentes independentes; (iii) criação de uma filial de vendas; e (iv) criação de uma planta de fabricação estrangeira. Além disso, os autores afirmam que o início da internacionalização, geralmente, demora alguns anos para acontecer, por conta, principalmente, dos riscos ao ingressar em mercados pouco conhecidos e da falta de experiência das organizações.

Entretanto, com o transcorrer dos anos e a mudança do ambiente global, o modelo original de Uppsala sofreu algumas críticas e surgiram outras abordagens para explicar o processo de internacionalização. Uma delas foi a Teoria do empreendedorismo internacional (EI). Morrow (1988) foi o primeiro a abordar essa temática (LEITE; MORAES, 2014) ao afirmar que o mundo estava entrando na "Era do empreendedorismo internacional".

O El é definido, por uma das abordagens, como o desenvolvimento de novos empreendimentos internacionais que, desde muito cedo, direcionam parte das suas atividades para o mercado internacional (MCDOUGALL, 1989). O horizonte de tempo para que a internacionalização possa ser considerada rápida deve ocorrer até os primeiros oito anos de fundação da empresa (MCDOUGALL; SHANE; OVIATT, 1994).

Nessa mesma linha de raciocínio, Rennie (1993) apresenta o conceito de Born Global. Pequenas e médias empresas que surgem, desde o início, voltadas para a internacionalização. Esses conceitos representaram uma quebra de paradigma, uma vez que, até a década de 1980, as pesquisas sobre internacionalização tinham como objetos de estudo grandes organizações que passavam por um processo incremental de internacionalização (JOHANSON; VAHLNE, 1977).

Com o passar do tempo, o conceito de El foi ampliado, não se restringindo mais ao tamanho ou à velocidade de internacionalização das empresas (ZAHRA; GEORGE, 2002; OVIATT; MCDOUGALL, 2005; DIMITRATOS; PLAKOYIANNAKI, 2003). Contribuindo com essa ampliação, Leite e Moraes (2012, p. 4) afirmam que o empreendedorismo internacional é "resultante do processo de exploração de oportunidades internacionais, da inovação, da atitude face ao risco e do desenvolvimento de recursos competitivos por parte do empreendedor para obter vantagem competitiva".

Em se tratando do terceiro modelo, ou a perspectiva de redes, percebe-se que o processo de internacionalização das empresas é influenciado ou é consequência da posição da organização nas redes internacionais (FORSGREN, 2008). As decisões estratégicas serão determinadas direta ou indiretamente pelas relações desenvolvidas pela empresa. As atividades de rede garantem o acesso a pessoas e organizações que exercem um papelchave, e que podem oferecer conhecimentos e contatos que, por sua vez, poderão contribuir no desenvolvimento do mercado-alvo (WELCH; WELCH, 2004).

Nesse sentido, Johanson e Vahlne (2009) revisitam o seu modelo original e ampliam o seu entendimento sobre o processo de internacionalização. Os autores afirmam, por exemplo, que a entrada em mercados internacionais não depende apenas do conhecimento, da distância psíquica e das capacidades internas da organização, mas também do seu posicionamento em uma rede. Os mercados são redes de relações em que as empresas estão ligadas umas às outras, em padrões invisíveis, e que a participação em redes relevantes é importante para a internacionalização (JOHANSON; VAHLNE, 2009). 
Aúltima revisão realizada por Johanson e Vahlne do modelo de Uppsala foi realizada em 2017 (VAHLNE; JOHANSON, 2017). Nessa revisão, os autores adotaram o conceito de "empresa multinacional de negócios" e apresentaram ideias relacionadas ao contexto dinâmico em que as empresas estão inseridas, além de explicações da trajetória de internacionalização baseadas em processo, ao invés de estruturas orientadas. Além disso, Vahlne e Johanson (2017) atualizaram o modelo por meio da inserção de conceitos mais adequados ao contexto atual, como empreendedorismo, proatividade, redes e aprendizagem experiencial.

Entretanto, já existem algumas críticas ao novo modelo proposto por Vahlne e Johanson (COVIELLO; KANO; LIESCH, 2017, HAKANSON; KAPPEN, 2017). Coviello, Kano e Liesch (2017) se concentram em duas dimensões ausentes no modelo de Uppsala revisado, o impacto do contexto digital e o papel do indivíduo como aspecto central no processo de internacionalização. Enquanto Hakanson e Kappen (2017) propuseram um modelo alternativo, o "modelo Cassino". Eles sugerem, ao contrário do modelo de Uppsala, que a internacionalização geralmente é realizada em uma frente ampla, com entradas simultâneas em diversos mercados, contribuindo para a identificação de oportunidades em mercados estrangeiros e na diminuição dos riscos, já que ocorre uma diversificação da aplicação dos recursos da empresa (HAKANSON; KAPPEN, 2017).

A seguir é apresentada a relação entre aprendizagem e internacionalização.

\subsection{Aprendizagem e Internacionalização}

A aprendizagem e a aquisição de conhecimento são temas abordados há algum tempo na literatura de internacionalização (JOHANSON; VALHNE, 1977). A aprendizagem desempenha um papel importante no contexto de estudo dos negócios internacionais, principalmente porque para ter êxito, as empresas precisam se adaptar cada vez mais rápido aos desafios do mundo globalizado (CAVUSGIL; KNIGHT; RIESENBER, 2016). Além disso, a mudança de paradigma provocada pelo El também contribuiu, de certa forma, para o aumento das discussões sobre o papel da aprendizagem nos processos de internacionalização (KEUPP; GASSMANN, 2009), pois se percebeu que dependendo do conhecimento e do tipo de aprendizagem, a internacionalização acontece de diferentes formas.

Antes de destacar a influência da aprendizagem no processo de internacionalização, é importante descrever alguns tipos de aprendizagem abordados na literatura de negócios internacionais. Dentre os vários tipos de aprendizagem estudados no El, destacam-se: (i) a aprendizagem experiencial - aprender com a experiência ou atividades, com subcomponentes que incluem experimentação, aprendizagem não sistemática ou não intencional; (ii) a aprendizagem vicária - aprender observando outras organizações; (iii) a pesquisa - procurar saber informações sobre o ambiente da organização; (iv) a aprendizagem enxertia - adição de componentes que possuem conhecimento necessário e que ainda não são possuídos pela organização; (v) a aprendizagem congênita - baseia-se no conhecimento e nas experiências dos fundadores, adquiridos por meio de suas atividades anteriores (HUBER, 1991).

Apesar de essas definições terem sido realizadas há mais de duas décadas, alguns estudos atuais no campo de negócios internacionais se baseiam nelas para construir ideias, teorias e para explicar alguns resultados importantes (DE CLERCQ et al., 2012, CASILLAS; BARBERO; SAPIENZA, 2014). Diante desse contexto, percebe-se uma variedade de tipos de aprendizagem que podem interferir no processo de internacionalização, a depender do tamanho das empresas, do ramo de atuação, da velocidade de internacionalização e do estágio em que a empresa se encontra (DE CLERCQ et al., 2012).

Comparando a internacionalização incremental com a internacionalização precoce, observa-se que a aprendizagem tem um papel diferente em cada uma. No processo incremental (JOHANSON; VALHNE, 1977), a aprendizagem experiencial é o mecanismo central que estimula ou inibe o processo de internacionalização. Por outro lado, na internacionalização precoce, principalmente no início do processo, outros tipos de aprendizagem apresentam-se de maneira mais consistente e relevante, como a aprendizagem que os fundadores já possuem (congênita) e a aprendizagem e o conhecimento obtidos por meio da rede (vicária).

Portanto, no modelo de Uppsala, o que importa são as experiências vividas após a internacionalização (aprendizagem experiencial), enquanto no El são as experiências vividas antes da internacionalização 
(aprendizagem congênita) que se destacam. Entretanto, esses dois tipos de aprendizagem se relacionam entre si, pois, o que os gerentes aprendem e suas interpretações dependem do conhecimento previamente adquirido (VAHLNE; JOHANSON, 2017).

Ademais, no modelo de Uppsala (JOHANSON; VAHLNE, 1977), em que a aprendizagem experiencial determina o ritmo da internacionalização, percebe-se que a falta de experiência e conhecimento são obstáculos para exploração de oportunidades além das fronteiras nacionais, uma vez que as empresas tendem a evitar incertezas e acabam explorando apenas aquelas regiões em que possuem mais conhecimento. Além disso, percebe-se que a aprendizagem experiencial é um processo que se desdobra ao longo do tempo e que tem que ser consolidado tanto na mente dos indivíduos quanto nas rotinas organizacionais (VAHLNE; JOHANSON, 2017).

Com o avanço do processo de internacionalização e consequente aumento da aprendizagem experiencial, uma vez que a empresa passa a vivenciar as suas próprias experiências, há uma diminuição da importância do papel exercido pelo conhecimento prévio dos fundadores da organização. Esse efeito transitório e temporal também pode ser observado com relação à aprendizagem ocorrida por meio das relações interorganizacionais (redes) (BRUNEEL; YLI-RENKO; CLARYSSE, 2010). Portanto, o conhecimento congênito influencia de maneira mais intensa as empresas mais jovens. À medida que o tempo avança e a empresa vai adquirindo outros tipos de conhecimento e aprendizagem, o efeito da aprendizagem congênita vai perdendo força (CASILLAS; BARBERO; SAPIENZA, 2014).

\section{Procedimentos Metodológicos}

Esta é uma pesquisa de natureza qualitativa (MERRIAM; TISDELL, 2016). Utiliza-se uma abordagem de estudo de caso, cuja intenção é capturar a complexidade e explorar as particularidades desse caso único (PATTON, 2002), compreendendo as suas atividades dentro de circunstâncias importantes (STAKE, 1995).

Os critérios para escolha do caso foram baseados em aspectos relacionados à dimensão da empresa, à atuação no mercado externo, à localização geográfica e à idade. Além disso, foi considerado também a facilidade de acesso e de obtenção de informações por parte do pesquisador, pois, como argumenta Stake (1995), devem-se investigar casos que são de fácil acesso e hospitalidade e que sejam potenciais fontes de aprendizagem.

A escolha dos sujeitos sociais para a entrevista foi realizada por meio do método não probabilístico intencional (CRESWELL, 2010). Assim sendo, foram escolhidos indivíduos que participaram ou ainda participam do processo de internacionalização da empresa, independentemente do cargo ocupado, conforme apresentado no quadro 1. Com o intuito de preservar a identidade dos entrevistados, os nomes utilizados são fictícios.

Quadro 1 - Perfil dos Entrevistados

\begin{tabular}{|l|l|c|}
\hline Entrevistado & \multicolumn{1}{|c|}{ Cargo que ocupa (ou ocupou) } & $\begin{array}{c}\text { Tempo de empresa } \\
\text { (aproximado) }\end{array}$ \\
\hline Frederico & Presidente & 43 anos \\
\hline Carlos & $\begin{array}{l}\text { Ex-Diretor Comercial de Exportação e atual Diretor de } \\
\text { Baterias Industriais }\end{array}$ & 32 anos \\
\hline Jorge & $\begin{array}{l}\text { Ex-Gerente de Exportação e atual sócio proprietário de um } \\
\text { Centro de Distribuição Moura }\end{array}$ & 30 anos \\
\hline Bernardo & Ex-Gerente de Exportação e atual Diretor Financeiro & 14 anos \\
\hline Fernanda & Coordenadora Comercial de Exportação & 7 anos \\
\hline Rodolfo & Analista de Exportação & 1 ano \\
\hline Caio & Analista de Exportação & 2 anos \\
\hline
\end{tabular}

Fonte: Elaborado pelos autores (2018) 
O principal instrumento de coleta dos dados foi a entrevista semiestruturada, pois por meio dela são "[...] preparadas várias perguntas que cobrem o escopo pretendido da entrevista" (FLICK, 2013 p. 115). As entrevistas foram realizadas entre os meses de julho e dezembro de 2017. Todas elas foram gravadas e transcritas, exceto a do diretor financeiro Bernardo, que não autorizou a gravação, mas se mostrou bastante solícito em responder e dirimir qualquer tipo de dúvida. Além das entrevistas, os dados foram coletados por meio da pesquisa documental (sites, revistas eletrônicas, matérias publicadas) e da investigação bibliográfica (teses, dissertações e artigos).

A análise dos dados foi realizada por meio do método da comparação constante (MERRIAM; TISDELL, 2016). Uma das principais formas de analisar os dados numa pesquisa qualitativa é realizando a análise e a coleta simultaneamente (MERRIAM; TISDELL, 2016). Tal procedimento foi adotado neste estudo. A partir da realização de cada entrevista, ela era transcrita e seus dados já começavam a ser codificados antes mesmo da realização da entrevista subsequente.

A codificação inicial foi realizada considerando incidente por incidente (CHARMAZ, 2009). A maior parte dos códigos iniciais foi modificada à medida que as entrevistas eram realizadas, e foram sendo aglutinados para construir categorias e, consequentemente, respostas mais coerentes e consistentes à pergunta de pesquisa.

Após a realização da codificação inicial, foram elaborados memorandos, que podem ser considerados "uma etapa intermediária fundamental entre a coleta de dados e a redação dos relatos de pesquisa" (CHARMAZ, 2009, p. 106). Esses documentos continham as principais observações e impressões dos pesquisadores sobre os dados de cada entrevista e contribuíram para reflexão e abstração. No total, foram produzidos sete memorandos, que ajudaram a entender as conexões e a construir um sentido lógico para o volume de informações. Além da codificação inicial e da elaboração de memorandos, foi realizada uma codificação focalizada, que representa a segunda fase principal da codificação (CHARMAZ, 2014) e é mais seletiva e conceitual do que a codificação inicial (CHARMAZ, 2009).

A codificação focalizada permitiu o retorno aos dados e a seleção daquelas informações mais relevantes para a construção das categorias de resposta. A partir dessa ação, algumas categorias foram se consolidando, enquanto outras não se mostraram relevantes ou se aglutinaram para formar uma categoria mais robusta. A seguir, no quadro 2, são apresentadas as categorias e as subcategorias que se consolidaram durante 0 processo de coleta e análise dos dados.

Quadro 2 - Categorias e subcategorias de análise

\begin{tabular}{|l|l|}
\hline Categorias & Subcategorias \\
\hline \multirow{3}{*}{ Buscando conhecimento } & Fundando a empresa \\
\cline { 2 - 2 } & Realizando intercâmbio com o exterior \\
\hline \multirow{4}{*}{ Exportando para o Hemisfério Norte } & Exportando para os EUA \\
\cline { 2 - 2 } & Abrindo escritório em Porto Rico \\
\cline { 2 - 2 } & Exportando para Europa \\
\cline { 2 - 2 } & Inaugurando a Moura Export \\
\hline \multirow{2}{*}{ Focando na América do Sul } & Operando na Argentina \\
\cline { 2 - 2 } & Explorando os demais países da América do Sul \\
\hline
\end{tabular}

As categorias e subcategorias serão exploradas e desenvolvidas na análise e discussão dos resultados.

\section{Análise e Discussão dos Resultados}

Nesta seção, primeiramente, é apresentada a história da empresa de maneira sintética. Posteriormente, é apresentado, discutido e analisado, o processo de internacionalização da Moura, o qual é dividido em três partes: (i) buscando conhecimento, (ii) exportando para o Hemisfério Norte e (iii) focando na América do Sul. 


\subsection{História da Empresa}

A Acumuladores Moura S.A. foi fundada em 1957, na cidade de Belo Jardim, pelo Sr. Edson Mororó Moura e a sua esposa, a Sra ${ }^{a}$. Maria da Conceição Moura, ambos formados em Engenharia Química pela Universidade Federal de Pernambuco (UFPE). A cidade fica no agreste pernambucano, a $187 \mathrm{~km}$ da cidade de Recife, capital do estado. Região humilde e que, principalmente na década de 1950, não possuía estrutura e recursos para que uma fábrica de baterias prosperasse. Mal possuía água e energia elétrica, e não havia um mercado para atender a oferta de um produto desse tipo. Na época, Pernambuco possuía menos de 500 carros e havia apenas um carro na cidade de Belo Jardim (NEJAIM, 2011).

Apesar do início difícil e complicado, atualmente, a Moura é uma das líderes no fornecimento de baterias automotivas para o mercado de montadoras, tanto no Brasil quanto na Argentina. Em ambos os países a empresa tem $50 \%$ do mercado, ou seja, a cada dois carros fabricados no Brasil e na Argentina, um possui a bateria Moura. A empresa fornece para as principais montadoras do mundo: Fiat, Ford, Volkswagen, Iveco, Mercedes-Benz, General Motors, Nissan, entre outras. Além disso, a Moura também é líder no mercado de reposição no Brasil, com cerca de $40 \%$ do marketshare. É importante salientar que o foco da empresa é justamente o mercado de reposição, que representa $70 \%$ do faturamento da organização.

Para atender esses mercados, a Moura possui 6 plantas industriais, quatro em Belo Jardim/PE, uma em Itapetininga/SP e outra em Pilar, na Argentina. A empresa, hoje, tem uma capacidade produtiva de mais de 7,5 milhões de baterias por ano (MOURA, 2017). Ao longo dos próximos anos, a organização pretende dobrar sua capacidade produtiva por meio da construção de uma nova planta industrial, na cidade de Belo Jardim, chamada de Unidade 10.

Além disso, a empresa possui 82 centros de distribuição próprios, sendo um no Uruguai, 7 na Argentina e 74 espalhados pelo Brasil. A rede emprega quase 2.000 mil pessoas no Brasil e tem como principal função distribuir a produção no mercado de reposição.

Conforme narrado por alguns entrevistados, esse tipo de distribuição própria é um dos grandes diferenciais da Moura perante os principais concorrentes, que, por sua vez, não utilizam esse modelo. Esse formato de distribuição permite que a empresa tenha controle sobre toda a cadeia de valor do produto, aproximando o seu relacionamento com os clientes finais. Desse modo, a empresa consegue trabalhar a marca e garantir assistência técnica e serviços de qualidade aos clientes.

Além da rede própria, a Moura conta com distribuidores independentes espalhados por alguns países da América Latina, como Bolívia, Paraguai, Colômbia, Suriname, Guiana, entre outros. Estes distribuidores independentes não vendem exclusivamente baterias Moura, eles podem importar de outros fabricantes e vender outras marcas.

Atualmente, a empresa trabalha com o seguinte portfólio de produtos: baterias para carros, baterias estacionárias (utilizadas para sistemas UPS (nobreaks), centrais telefônicas, alarmes, sistemas de som, energia solar e eólica, iluminação de emergência ou qualquer outra aplicação que demande uma corrente moderada por mais tempo), tracionárias (utilizadas em empilhadeiras e veículos elétricos, como carrinhos de golf), náuticas, para motos e para ônibus e caminhões.

A próxima seção descreve o processo de internacionalização da Moura e as suas respectivas fases.

\subsection{Processo de Internacionalização}

As primeiras exportações da empresa aconteceram na década de 1980 (BARBOSA; MORAES, 2008). Entretanto, é importante destacar que o processo de internacionalização da Moura está vinculado a fatores anteriores às exportações iniciais (BARBOSA, 2008). A seguir, a figura 1 apresenta as fases de internacionalização da empresa até o ano de 2007. 
Figura 1 - Mudanças e continuidades das estratégias internacionais da Acumuladores Moura S/A.

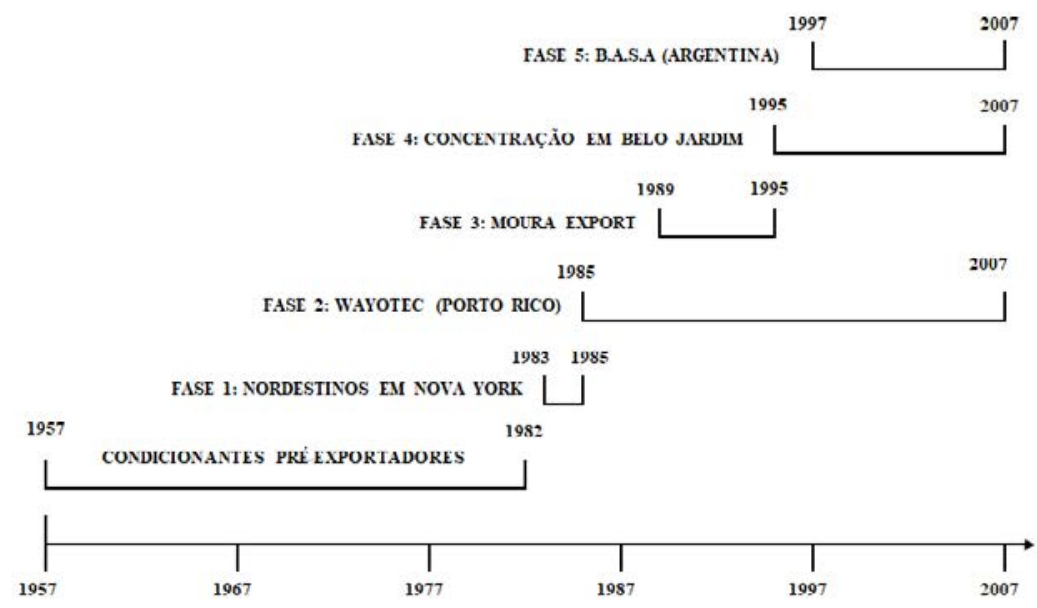

Fonte: Barbosa e Moraes (2008)

A figura 1 foi utilizada como base para a construção e a compreensão do processo de internacionalização da Moura neste artigo. Entretanto, é importante salientar que algumas alterações foram realizadas, tendo em vista, principalmente, que os objetivos dos estudos são diferentes e que, por conta disso, a delimitação de algumas fases não foi igual, assim comosuas definições.

A fase denominada "Condicionantes pré-exportadores" representa a busca de conhecimentos tecnológicos por parte do fundador para a melhoria da empresa até conseguir realizar as suas primeiras exportações. A fase 1, "Nordestinos em Nova York", representa o início das transações comerciais com o exterior, especificamente com os EUA. Nessa fase, a empresa também instalou um escritório comercial em Nova York. A segunda fase, "Wayotec (Porto Rico)", foi consequência do fracasso da entrada nos EUA. O escritório foi transferido para Porto Rico.

$\mathrm{Na}$ fase 3, "Moura Export", a empresa decidiu inaugurar uma fábrica cuja produção foi totalmente voltada para o mercado externo. O encerramento das atividades nessa fábrica, em 1995, deu início a um período de concentração da produção em Belo Jardim (Fase 4). Por fim, em 1997, a Moura decidiu criar a B.A.S.A (Baterias Argentinas S. A.), cujo principal objetivo era atender ao mercado argentino que estava se tornando cada vez mais importante para os negócios internacionais da empresa.

Neste artigo, o processo de internacionalização da Moura foi dividido em três fases: (i) buscando conhecimento; (ii) exportando para o Hemisfério Norte; e (iii) focando na América do Sul (figura 2). As diferenças para o estudo de Barbosa e Moraes (2008) são consequências, basicamente, de questões didáticas, uma vez que o processo de internacionalização é o mesmo, mas a análise e o ponto de vista é que são diferentes. A fase 1, "Buscando conhecimento", corresponde ao que Barbosa e Moraes (2008) definiram como "Condicionantes pré-exportadores". Enquanto que a fase 2, "Exportando para o Hemisfério Norte", corresponde às fases 1, 2 (somente a parte inicial) e 3 da figura 1. Por fim, a fase 3, "Focando na América do Sul", corresponde às fases 4 e 5 de Barbosa e Moraes (2008).

Figura 2 - Fases do processo de internacionalização da Moura

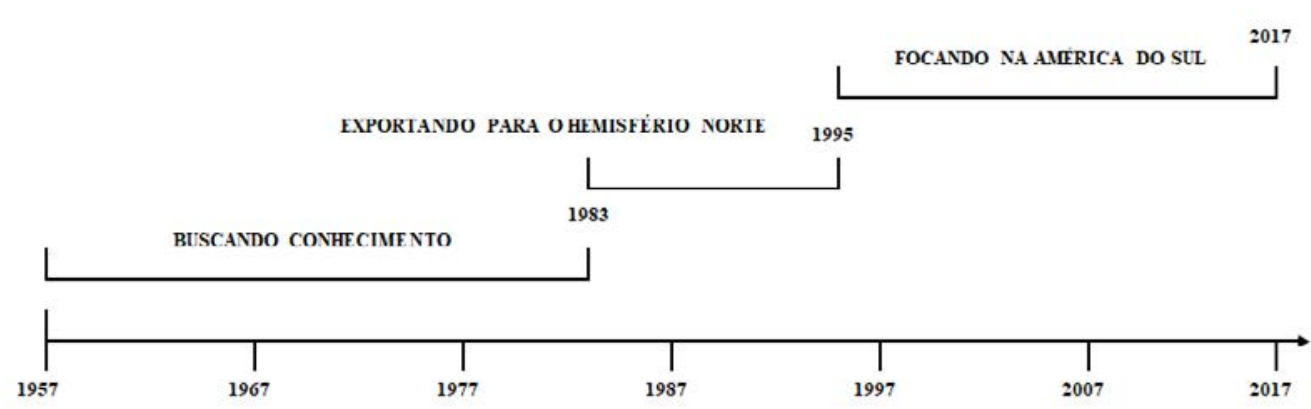

Fonte: Elaborado pelos autores (2018) 
Na sequência é detalhada cada fase desse processo.

\subsubsection{Buscando Conhecimento}

Essa primeira fase se inicia juntamente com a fundação da empresa, em 1957, e descreve a busca incessante por conhecimento, que, por sua vez, viabilizou e possibilitou o crescimento da empresa nas suas primeiras décadas. O fundador da empresa possuía o desejo de abrir uma fábrica de baterias, mas não conhecia quase nada sobre o assunto, basicamente, só conhecia as leis gerais que regem a parte técnica (BARBOSA, 2008). Entretanto somente a vontade e o desejo não bastavam para que o Sr. Edson Mororó Moura concretizasse a ideia de construir uma fábrica de baterias.

Na busca pelo conhecimento necessário para abrir a fábrica e desenvolver os produtos, primeiramente, o Sr. Edson Moura procurou os seus professores da Universidade Federal de Pernambuco (UFPE), que fizeram duas cartas de recomendação: uma para um estágio na empresa Satúrnia, uma das maiores fábricas de baterias do país à época, e outra indicando um professor da USP para ajudá-lo na empreitada (BARBOSA, 2008). Assim que o dono da Satúrnia soube do real motivo da visita (abrir uma fábrica de baterias em Pernambuco), cancelou o estágio.

Sr. Edson resolveu utilizar a outra carta de recomendação e encontrou o professor da USP, que, por sua vez, o apresentou a um homem que havia trabalhado por 10 anos na Prestolite, uma fábrica de baterias. A partir desse contato, Sr. Edson visitou algumas fábricas em São Paulo e conseguiu contratar um operário, especialista em montagem de baterias, para ajudar a implantar a fábrica em Belo Jardim. Nesse primeiro momento, percebe-se a influência de dois tipos de aprendizagem, das redes e da enxertia, com a contratação de um profissional para suprir a deficiência da organização (HUBER, 1991).

Segundo o Sr. Edson Moura, "[...] a quantidade de conhecimentos que nós trouxemos de São Paulo foi bastante para construir uma planta muito pequena e muito ineficiente [...]" (BARBOSA, 2008, p. 76). No início, as baterias eram de baixíssima qualidade. Entretanto, em 1967, o fundador realizou um intercâmbio nos EUA e na Inglaterra, financiado pela USAID, organização americana, implementada em 1961 pelo governo do presidente Kennedy, que estimulava e proporcionava condições dos empresários nordestinos visitarem fábricas instaladas no exterior, com a finalidade de trocar informações e obter algum tipo de aprendizado.

O Sr. Edson Moura e a sua esposa viajaram por cerca de três meses nos dois países e puderam perceber o quanto estavam distantes em termos de tecnologia e conhecimento. Na Inglaterra, eles conseguiram fechar uma parceria com uma fábrica de baterias, a Chloride. A parceria funcionava da seguinte forma: a Chloride enviava literatura especializada e alguns técnicos ingleses passavam alguns períodos por ano na fábrica em Belo Jardim, em troca, a Moura fornecia um percentual das suas vendas.

Formalmente, a parceria durou cinco anos, de 1967 a 1972, e significou um avanço bastante relevante na qualidade da bateria produzida pela Moura. Entretanto, segundo o próprio fundador, devido à quantidade elevada de informações enviadas pela Chloride atrelada à falta de conhecimento da Moura, cerca de $80 \%$ do conhecimento era perdido durante a troca de informações (BARBOSA, 2008).

Mesmo não aproveitando $100 \%$ do conhecimento que a Chloride tinha para oferecer, a Moura se desenvolveu. Esse crescimento permitiu que a empresa começasse a realizar alguns contratos com as principais montadoras multinacionais que estavam ingressando no Brasil, a primeira delas foi a Fiat.

Esses contratos representaram um "selo de qualidade" para a empresa, uma vez que, para fornecer às montadoras, era necessário cumprir uma série de requisitos internacionais. Isto, por sua vez, também fez com que a Moura começasse a amadurecer e a se preparar para atender às exigências do exterior.

Portanto, por meio da busca de conhecimento por parte do fundador da empresa, foi possível realizar parcerias e contratos que contribuíram para o início da empresa propriamente dito, assim como para começar a enxergar além das fronteiras nacionais. Esse fato corrobora com o que Johanson e Vahlne (2009) argumentam, que o conhecimento construído por meio das redes pode ser importante para o sucesso da organização.

O final dessa fase é marcado pela realização das primeiras exportações. A partir do ano de 1983, começaram a acontecer as primeiras transações comerciais, e não apenas a troca de conhecimento. 


\subsubsection{Exportando para o Hemisfério Norte}

Esta fase se inicia no ano de 1983, quando ocorreram as primeiras exportações da empresa. Assim como a fase anterior, também é fruto primordialmente do desejo do fundador e empreendedor, Sr. Edson Mororó Moura, de ingressar em mercados desafiadores, que pudessem contribuir para a aprendizagem da organização. "O Dr. Edson Moura sempre acreditou que a Moura deveria em algum momento, pra se tornar uma empresa grande, a Moura deveria experimentar o mercado externo. E a gente deveria aprender com o mercado externo", argumenta Jorge, ex-gerente de exportação.

Portanto, a Moura realizou suas primeiras exportações para os EUA, o maior mercado de baterias automotivas da época. "E lá fomos nós, com um amadorismo tremendo, com uma inexperiência imensa, para o mercado mais desenvolvido do mundo e repleto de fabricantes locais", descreve Carlos, ex-diretor comercial de exportação. Esse fato corrobora com a literatura de El, que argumenta que a entrada da empresa no mercado estrangeiro, na maioria das vezes, é consequência do comportamento individual do empreendedor (MTIGWE, 2006).

Para o Sr. Edson Moura, ir para países da América do Sul não representava nenhum grande desafio, e o potencial de aprendizagem era muito menor do que ir para o principal país do mundo. "[...] Ele (Sr. Edson Moura) não considerava uma vitória vender para Argentina. O desafio era vender para Inglaterra, vender para os EUA, para o Hemisfério Norte, onde o mercado é muito maior", afirma Frederico, um dos atuais presidentes da empresa.

Percebe-se que essa primeira iniciativa concreta de internacionalização foi fruto, basicamente, do arrojo empresarial do fundador da empresa, aproximando-se das ideias da teoria do El, que argumenta que a velocidade de internacionalização empresarial é influenciada por várias forças, dentre elas, a percepção mediadora dos empreendedores (OVIATT; MCDOUGALL, 2005). Ao mesmo tempo, essa ação de exportar primeiro para os EUA vai de encontro ao que defende a escola de Uppsala, que a probabilidade de iniciar a internacionalização para países com grandes distâncias psíquicas é muito pequena, pois a falta de conhecimento sobre o mercado age como um obstáculo para essa empreitada (JOHANSON; VALHNE, 1977).

Além disso, Clark, Li e Shepherd (2018) argumentam que, geralmente, no início da internacionalização, os gestores costumam selecionar países com os quais possuem maior familiaridade. Esse argumento evidencia o percurso diferente e, até certo ponto inusitado, adotado pelo fundador da Moura, uma fez que ele não possuía um conhecimento acurado sobre o mercado norte-americano.

Percebe-se, com esse fato, que o processo de internacionalização da empresa está diretamente relacionado ao pensamento e à vontade do fundador da organização. Nesse sentido, corroborando com as ideias de Coviello, Kano e Liesch (2017), nota-se que, para entender o comportamento de internacionalização da empresa, é necessário entender o indivíduo que dirige a empresa; deslocando, com isso, a análise do nível macro para o micro.

Ademais, diferentemente da literatura de $\mathrm{El}$, em que muitas vezes a aprendizagem representa uma consequência da internacionalização (CASILLAS; BARBERO; SAPIENZA, 2014), para o Sr. Edson Moura ela representava a causa, o motivo da internacionalização, deixando em segundo plano, muitas vezes, o desempenho financeiro da organização no exterior. Ao ingressar em mercados internacionais, na maioria dos casos, os empreendedores são impelidos a aprender, a fim de construir as capacidades necessárias para manter sua posição competitiva (DIMITRATOS; PLAKOYIANNAKI, 2003), mas não significa dizer que o motivo principal da internacionalização é a aprendizagem.

Nos dois anos em que passou exportando para os EUA, a empresa acumulou prejuízos. O insucesso pode ser atribuído a vários fatores: a bateria produzida na Moura seguia um modelo europeu, que era diferente do padrão americano e, por sua vez, não encaixava nos carros americanos, tendo que sofrer adaptações; a bateria não era apropriada para climas frios; o gestor que saiu do Brasil para gerenciar o negócio em Nova York não se adaptou; e a empresa também enfrentou algumas dificuldades logísticas. Em síntese, talvez por conta da falta de experiência, de uma tecnologia adequada ao mercado americano e da grande distância psíquica, as dificuldades tenham sido enormes. 
Apesar do grande aprendizado, o insucesso econômico fez com que a empresa declinasse das investidas no mercado americano. No entanto, por meio de um funcionário portoriquenho que trabalhava na Moura Battery, surgiu a ideia de ir para Porto Rico, local com uma cultura mais próxima da brasileira e com uma mão de obra mais barata do que a americana, proporcionando maior competitividade para a Moura. Decidiu-se, então, fechar o escritório em Nova York e transferi-lo para Porto Rico.

Nessa fase de imersão nos mercados dos EUA e de Porto Rico, a Moura descobriu uma oportunidade para se tornar mais competitiva, que foi a importação de sucata de bateria. Entretanto, em 1995, o governo brasileiro proibiu a importação dessas sucatas, por acreditar que, na verdade, se tratava de lixo e que poderia trazer alguns malefícios para o Brasil. Essa medida adotada pelo governo brasileiro fez com que a Moura perdesse competitividade, uma vez que o chumbo é a principal matéria-prima da bateria e, sem a possibilidade de importar a sucata, o custo do chumbo para uma empresa brasileira aumentava. Dessa forma, o mercado de Porto Rico passou a ser menos atrativo.

Além dos mercados dos EUA e de Porto Rico, a Moura também tentou se instalar no mercado da Europa, no final da década de 1980 e início da década de 1990. Mas esse movimento de internacionalização também não apresentou sucesso financeiro.

Diante desse contexto, é possível perceber que esse primeiro movimento concreto de internacionalização da Moura ocorreu de uma forma mais incremental e pouca planejada. Ela foi fruto, principalmente, do desejo do fundador de inserir a empresa no mercado internacional. De acordo com a Teoria do El, o desejo, a iniciativa e o espírito arrojado do empreendedor, combinados com a busca de vantagem competitiva, é que fazem com que a empresa atravesse as fronteiras em busca de oportunidades (MCDOUGALL; OVIATT, 2000). No entanto, esse espírito impetuoso do empreendedor, em curto prazo, acabou prejudicando os resultados financeiros da organização, o que vai de encontro ao que a Teoria de El defende.

Portanto, devido à fase embrionária, à falta de planejamento e às dificuldades naturais ao se instalar em mercados distantes fisicamente e psiquicamente (JOHANSON; VALHNE, 1977), esse primeiro movimento de internacionalização não foi um sucesso economicamente, embora tenha sido proveitoso em termos de aprendizagem e conhecimento.

Nesse período, em que o principal foco internacional da empresa era exportar para o Hemisfério Norte, onde estavam os maiores centros automobilísticos da época, a Moura decidiu abrir uma planta para fabricação de baterias voltadas, exclusivamente, para o mercado externo. Como as exigências internacionais eram diferentes das exigências nacionais, seja por conta do clima, dos moldes das baterias, seja por questões culturais, decidiu-se que era necessário ocorrer essa separação entre as baterias para o mercado interno e para o mercado externo. Essa decisão corrobora com os argumentos de Dimitratos e Plakoyiannaki (2003), de que o empreendedorismo internacional tem que ser incorporado à cultura organizacional da empresa. $\mathrm{Na}$ visão desses autores, a cultura empresarial internacional facilita e acomoda as atividades empresariais no mercado internacional.

Sendo assim, em 1989, em Suape, município de Ipojuca/PE, inaugurou-se a Moura Export. Esse movimento, ao contrário dos anteriores, ocorreu de maneira planejada e deliberada, e não foi fruto apenas do arrobo empreendedor do Sr. Edson Moura. Houve uma grande mobilização financeira para montar a nova fábrica, no entanto os resultados não corresponderam às expectativas. Após três anos de resultados negativos, percebeu-se que a empresa não estava preparada para essa escolha estratégica.

Concluiu-se, também, que a solução para as exportações não era criar uma nova fábrica, mas preparar a unidade de Belo Jardim para satisfazer a demanda e os requisitos internacionais. Portanto, construir uma cultura internacional não significava, necessariamente, construir uma nova fábrica. Decidiu-se fechar a Moura Export, em 1995, e as operações internacionais foram concentradas na fábrica de Belo Jardim.

Por conseguinte, é possível afirmar que o fechamento da Moura Export representou o final de uma fase internacional em que a empresa foi guiada pelo desejo do fundador e que as estratégias eram emergentes e os resultados financeiros não eram satisfatórios. A Moura Export representou uma mudança significativa para a gestão e o planejamento estratégico da empresa. As ações estratégicas passaram a ser mais deliberadas e, com isso, a empresa passou a realizar escolhas mais racionais e rentáveis, como a centralização da 
produção em Belo Jardim, para ganhar economia de escala, e a saída de alguns mercados internacionais que não geravam lucro.

\subsubsection{Focando na América do Sul}

A partir da segunda metade da década de 1990, após os insucessos nos EUA, em Porto Rico e na Europa, a empresa começou a rever seus investimentos internacionais e passou a ser mais conservadora e cautelosa. A empresa foi direcionando suas ações para o mercado da América do Sul, que, potencialmente, poderia ser mais rentável.

Nesse entremeio, a Moura ganhou a conta da Ford no Brasil e na Argentina. Assim, precisava ter uma base de operação que auxiliasse nas entregas das baterias para a Ford na Argentina. Entretanto, talvez por conta dos insucessos anteriores, a gestão da empresa estava relutante em iniciar uma base de operações na Argentina. Dewey (1938) afirma que a experiência é algo singular que marca o indivíduo e faz com que ela seja lembrada posteriormente. Nesse sentido, as experiências anteriores marcaram negativamente os empreendedores e os deixaram receosos em investir recursos nessa nova oportunidade.

Pode-se afirmar que a Moura foi aprendendo com os erros e, à medida que o tempo passava, os empreendedores tornavam-se mais cautelosos e menos propensos a enfrentar os riscos de uma internacionalização. Portanto, ao contrário da literatura, com a aprendizagem e com o passar do tempo, a empresa, ao invés de aumentar os investimentos, começou a sair de alguns mercados que eram pouco rentáveis.

Sendo assim, com o intuito de economizar e se arriscar o mínimo possível, a Moura firmou uma parceria com uma empresa local, que faria o processo de acabamento e formação e realizaria a entrega para a Ford (Argentina), isto é, o processo de fabricação da bateria era iniciado em Belo Jardim e finalizado nessa empresa parceira na Argentina. No começo, o fornecimento aconteceu dessa maneira, entretanto a Ford começou a pressionar a Moura para que ela fosse para a Argentina, pois a qualidade do serviço prestado pela empresa parceira não estava de acordo com os padrões exigidos pela montadora.

Por conta desse ultimato, a Moura foi obrigada a instalar uma base na Argentina, que foi denominada de B.A.S.A (Baterias Argentinas S. A.) e era uma espécie de um depósito que realizava a última etapa de fabricação da bateria e a entregava para a fábrica da Ford.

A partir da instalação dessa unidade, a Moura enxergou uma oportunidade e procurou desenvolver o mercado argentino. A empresa conseguiu realizar outros contratos com montadoras, o que, de certa forma, contribuiu para que o mercado de reposição começasse a conhecer de maneira mais sólida a marca Moura. O foco da empresa foi sendo alterado do Hemisfério Norte para o Sul.

Nessa fase, percebe-se que a aprendizagem desempenhou um papel importante no processo de comprometimento de recursos, conforme argumenta Vahlne e Johanson (2017). A Moura diminuiu os investimentos nos EUA e na Europa, e passou a investir nos países da América do Sul, principalmente na Argentina. Nesse sentido, Vahlne e Johanson (2017) afirmam que as capacidades da empresa estão constantemente sendo alteradas e que a aprendizagem influencia a redução da diversificação, a saída de um mercado, o rompimento da relação com um parceiro, assim como a diminuição da alocação de recursos em determinada região, conforme aconteceu com a Moura.

A empresa não cresceu apenas na Argentina, ela desenvolveu uma estratégia para conquistar a liderança no mercado da América do Sul de uma forma gradativa, sólida e sustentável. Diferentemente das "aventuras" internacionais anteriores, que não apresentavam lucro, a estratégia de explorar o mercado da América do Sul se mostrou rentável.

Nesta fase é possível perceber que há uma preocupação com a exploração planejada dos mercados, com o crescimento equilibrado, com a rentabilidade e com o desenvolvimento da marca Moura. Um dos motivos que diferencia esta fase da fase inicial de exportação da empresa é que o foco passou a ser na rentabilidade e no potencial de crescimento da Moura em cada mercado.

O objetivo principal da empresa não é mais aprender e estar presente nos principais mercados mundiais a qualquer custo. Invariavelmente, a aprendizagem acontece, mas quando a empresa se lançou, 
por exemplo, no mercado dos EUA, um dos objetivos era aprender com um dos principais mercados de baterias automotivas do mundo e mostrar que a organização era capaz de fornecer para esse mercado. $\mathrm{O}$ objetivo, agora, é crescer de maneira sustentável e rentável.

Além disso, é possível perceber com a descrição dessas fases que o processo de internacionalização da Moura ocorreu gradativamente, tal qual argumentam os autores da escola de Uppsala (JOHANSON; VAHLNE, 1977). Ademais, na Argentina, observa-se que a Moura acabou percorrendo as quatro fases de internacionalização descritas por Johanson e Vahlne (1977), quais sejam: (i) não há atividades regulares de exportação; (ii) exportação por meio de agentes independentes; (iii) criação de uma filial de vendas; e (iv) criação de uma planta de fabricação estrangeira. Nesse sentido, à medida que o tempo foi passando, que o conhecimento sobre os mercados foi aumentando, o comprometimento de recursos da empresa com o mercado externo também ficou cada vez maior.

Nessa perspectiva, Bernardo, diretor financeiro e ex-gerente de exportação, acredita que a internacionalização da Moura foi um processo, que não teve um evento emblemático e que o importante foi o acúmulo de experiências no decorrer do caminho. "O acúmulo de sucessos e fracassos contribuiu para o amadurecimento da empresa no estabelecimento de estratégias no mercado internacional", explica Bernardo.

Portanto, é possível afirmar que a Moura se encontra nessa fase, "Focando na América do Sul", até os dias atuais, em que o foco principal dos negócios internacionais da empresa é na América do Sul e, de uma forma geral, na América Latina.

\section{Conclusão}

Desde a fundação da empresa a aprendizagem exerceu grande influência nas decisões estratégicas da Moura. No início, a busca pelo conhecimento guiou a organização e possibilitou que ela realizasse parcerias e encontrasse profissionais que pudessem contribuir para o seu desenvolvimento.

Entretanto, percebe-se que essa fase inicial pouco contribuiu para o desempenho da organização no mercado internacional. $O$ desejo do fundador de estar presente e aprender com os principais mercados de baterias do mundo fez com que a Moura seguisse alguns passos atípicos no processo de internacionalização.

No início, as empresas costumam procurar países com características culturais mais próximas às suas e com uma economia menos desenvolvida do que a sua (JOHANSON; VALHNE, 1977, 2009). Além disso, as empresas que se internacionalizam tardiamente costumam realizar essa transição quando já possuem liderança comercial no mercado interno, o que não foi o caso da Moura. Por fim, o motivo principal da internacionalização da empresa foi a busca de aprendizagem, quando, normalmente, busca-se rentabilidade e vantagens financeiras primeiramente. Conhecimento normalmente é consequência e não causa.

É interessante perceber também que o fundador não possuía uma rede de relacionamentos que contribuísse para entrada no mercado dos EUA e nos países da Europa. Alguns autores afirmam que as redes são utilizadas para contornar as dificuldades iniciais ocasionadas pela distância psíquica entre os países (JOHANSON; VALHNE, 2009), mas a Moura não possuía contatos que pudessem facilitar as suas ações. Mesmo assim, decidiu trilhar esse caminho.

Portanto, mesmo acontecendo de maneira gradual, o movimento de internacionalização do estudo de caso tem algumas características peculiares que o diferenciam do processo de internacionalização descrito pela escola de Uppsala, principalmente na sua fase inicial. Após esse primeiro momento, que foi baseado no desejo do empreendedor de aprender, a empresa reviu algumas estratégias e o "espírito empreendedor" começou a dividir espaço com o "espírito gestor". O evento crítico que simboliza bem essa mudança foi a decisão de concentrar a produção em Belo Jardim e sair daqueles mercados que não eram rentáveis para a empresa.

Diante do exposto, percebe-se que a aprendizagem experiencial foi importante para que a empresa revisasse as suas estratégias. Após os insucessos iniciais, a empresa alterou sua estratégia. O foco, então, já não era mais a aprendizagem, e sim a rentabilidade. A partir disso, pode-se dizer que foi outro processo, em que a empresa procurou mercados culturalmente mais próximos (América Latina), com um nível econômico parecido com o Brasil e, assim, conseguiu maiores retornos e também realizou maiores investimentos. 
Ademais, a partir da entrada nos mercados internacionais, as redes tiveram uma participação importante para a exploração de outras oportunidades, sendo por meio delas que a Moura identificou a oportunidade de ingressar no mercado de Porto Rico e, além disso, conseguiu fechar contratos com algumas montadoras de veículos, como a Ford, no Brasil e na Argentina.

Respeitando as limitações de uma pesquisa eminentemente qualitativa, de modo a ampliar as inferências desta investigação e na tentativa de trazer novos achados a respeito do que fora explorado neste artigo, sugere-se como propostas para pesquisas futuras: (i) realização de mais trabalhos longitudinais em países emergentes com o intuito de verificar o que converge e o que diverge dos achados dos estudos realizados nos países desenvolvidos; e (ii) mais estudos relacionados às teorias com abordagens comportamentais na área de negócios internacionais (escola de Uppsala, empreendedorismo internacional e a Teoria de redes).

\section{Referências}

BARBOSA, G. L. Análise do processo de formação de estratégias internacionais da Acumuladores Moura S.A. 2008. Dissertação (Mestrado em Administração) - Programa de Pós-Graduação em Administração, Universidade Federal de Pernambuco, Recife, 2008.

BARBOSA, G. L.; MORAES, W. F. A. O processo de formação de estratégias internacionais: o caso da empresa Acumuladores Moura S/A. In: SEMINÁRIOS EM ADMINISTRAÇÃO, 11., 2008, São Paulo.. Anais [...]. São Paulo: SEMEAD, 2008. p.1-16.

BRUNEEL, J.; YLI-RENKO, H.; CLARYSSE, B. Learning from experience and learning from others: How congenital and inter-organizational learning substitute for experiential learning in young firm internationalization. StrategicEntrepreneurshipJournal, [s.I.], v. 4, n. 2, p. 164-182, Jun. 2010.

CARNEIRO, J.; DIB, L. A. Avaliação comparativa do escopo descritivo e explanatório dos principais modelos de internacionalização de empresas. InternexT - Revista Eletrônica de Negócios Internacionais da ESPM, São Paulo, v. 2, n. 1, p. 1-25, jan./jun. 2007.

CASILLAS, J. C.; BARBERO, J. L.; SAPIENZA, H. J. Knowledge acquisition, learning, and the initial pace of internationalization. International Business Review, [s.I.], v. 24, n. 1, p. 1-13, Feb. 2014.

CAVUSGIL, S. T.; KNIGHT, G.; RIESENBERG, J. R. International Business. 4th edition. Londres, Reino Unido: Pearson Education, USA, 2016.

CHARMAZ, K. A construção da teoria fundamentada: guia prático para análise qualitativa. Porto Alegre: Artmed, 2009.

CHARMAZ, K. Constructing grounded theory. 2. ed. Los Angeles: Sage, 2014.

CLARK, D. R.; LI, D.; SHEPHERD, D. A. Country familiarity in the initial stage of foreign market selection. Journal of International Business Studies, [s.I.], v. 49, n. 4, p. 442-472, May, 2018.

COVIELLO, N.; KANO, L.; LIESCH, P. W. Adapting the Uppsala model to a modern world: Macro-context and microfoundations. Journal of International Business Studies, [s.I.], v. 48, n. 9, p. 1151-1164, Dec. 2017.

CRESWELL, J. W. Projeto de pesquisa: métodos qualitativo, quantitativo e misto. 3 ed. Porto Alegre: Artmed, 2010.

DE CLERCQ, D. et al. Learning and knowledge in early internationalization research: Past accomplishments and future directions. Journal of Business Venturing, [s.I.], v. 27, n. 1, p. 143-165, Jan. 2012.

DEWEY, J. Experience and education. New York: Collier Books, 1938.

DIMITRATOS, P.; PLAKOYIANNAKI, E. Theoretical foundations of international entrepreneurial culture. Journal of International entrepreneurship, [s.I.], v. 1, n. 2, p. 187- 
215, Jun. 2003.

DUNNING, J.H. Towards an ecletic theory of international production: some empirical tests. Journal of International Business Studies. [s.I.], v.11, n. 1, p. 9-31, Spring - Summer, 1980.

FLICK, U. Introdução a Metodologia de Pesquisa: um guia para iniciantes. Porto Alegre: Pensa, 2013.

FORSGREN, M. Theories of the multinational firm: a multidimensional creature in the global economy. Massachusetts: Edward Elgar Publishing Limites, 2008.

HAKANSON, L.; KAPPEN, P. The 'Casino Model' of internationalization: An alternative Uppsala paradigm. Journal of International Business Studies, [s.I.], v. 48, n. 9, p. 1103-1113, Dec. 2017.

HUBER, G. P. Organizational learning: the contributing process and the literatures. Organization Science, [s.I.], v. 2, n. 1, Special, p. 88-115, Mar. 1991.

JOHANSON, J.; VAHLNE, J. E. The internationalization process of the firm: a model of knowledge development and increasing foreign markets commitments. Journal of International Business Studies. [s.I.], v. 8, n. 1, p. 23-32, Mar. 1977.

JOHANSON, J.; VAHLNE, J. E. The Uppsala internationalization process model revisited: from liability of foreignness to liability of outsidership. Journal of International Business Studies, [s.I.], v. 40, n. 9, p. 1411-1431, Dec. 2009.

JOHANSON, J.; MATTSSON, L. G. Internationalization in industrial system: a network approach. In: HOOD, N.; VAHLNE, J. (eds) Strategies in global competition. Croom Helm, New York, 1988. p. 287314.

KEUPP, M. M.; GASSMANN, O. The past and the future of international entrepreneurship: a review and suggestions for developing the field. Journal of Management, [s.I.], v. 35, n. 3, p. 600-633, Jun. 2009

LEITE; Y. V. P.; MORAES, W. F. A. de. Empreendedorismo internacional: proposição de um framework. In: ENCONTRO DA ANPAD, 36., 2012, Rio de Janeiro. Anais [...] Rio de Janeiro: EnAnpad, 2012. CD-ROM.

LEITE, Y. V. P.; MORAES, W. F. A. de. Facetas do Risco no Empreendedorismo Internacional, Revista de Administração Contemporânea - RAC, Rio de Janeiro, v. 18, n. 1, p. 96-117, Jan./Fev., 2014.

MCDOUGALL, P. P. International versus domestic entrepreneurship: new venture strategic behavior and industry structure. Journal of Business Venturing, [s.I.], v. 4, n. 6, p. 387-400, 1989.

MCDOUGALL, P. P.; SHANE, S.; OVIATT, B. Explaining the formation of international new ventures: the limits of theories from international business research. Journal of Business Venturing, [s.I.], v. 9, n.6, p.469-487. 1994.

MCDOUGALL, P. P. International entrepreneurship: The intersection of two paths. Guest Editor's Introduction. Academy of Management Journal, [s.I.], v. 43, n. 5, p. 902-908, 2000.

Melhores e Maiores 2016. Revista Exame, São Paulo: Editora Abril, 2016. Disponível em: http://www. exame.abril.com.br. Acesso em: 27 maio 2017.

MERRIAM, S.; TISDELL, E. Qualitative research: a guide to design and implementation. San Francisco: Jossey-Bass, 2016.

MORROW, J. F. International entrepreneurship: A new growth opportunity. New

Management, [s.I.],v. 5, n. 3, p. 59-60, 1988. 
MOURA. Acumuladores Moura S/A. Baterias Moura. 2017. Disponível em: http://www.moura.com.br. Acesso em: 23 nov. 2017.

MTIGWE, B. Theoretical milestones in international business: the journey to international entrepreneurship theory. Journal of International Entrepreneurship, [s.I.], v. 4, n.1, p. 5-25, Mar. 2006. NEJAIM, D. Energia de sobra. Revista Negócios PE - Empresas, Mercados, Empresários e Executivos. Disponível em: http://www.revistanegociospe.com.br. Acesso em: 30 out. 2017.

OVIATT, B. M.; MCDOUGALL, P. P. The internationalization of entrepreneurship. Journal of International Business Studies, [s.I.], v. 36, n. 1, p. 2-8, Feb. 2005c.

OVIATT, B. M.; MCDOUGALL, P. P. Toward a theory of international new ventures. Journal of International Business Studies, [s.I.], v. 25, n. 1, p. 45-64, Mar. 1994.

PATTON, M. Q. Qualitative research e evaluation methods. $3^{\mathrm{a} e d .}$ California: Sage, 2002.

PEREIRA, J. A.; BÁNKUTI, S. M. S. Estrutura de mercado e estratégia: um estudo na indústria brasileira de baterias automotivas. Revista Ibero-Americana de Estratégia, São Paulo, v. 15, n. 1, p. 97-115, jan./ mar. 2016.

PEREIRA JUNIOR, E. Dinâmicas industriais e urbanização no Nordeste do Brasil. Mercator, Fortaleza, v. 14, n. 4, Número Especial, p. 63-81, dez. 2015.

PORTER, M. E. A vantagem competitiva das nações. In: PORTER, M. E. Competição: estratégias competitivas essenciais. 6 ed. Rio de Janeiro: Campus, 1999, p. 167-208.

RENNIE, M. W. Born Global.The McKinsey Quarterly, [s.I.], v. 4, p. 45-52, 1993.

SERVANTIE, V. et al. Is international entrepreneurship a field? A bibliometric analysis of the literature (1989-2015). Journal International Entrepreneurship, [s.I.], v. 14, n. 2, p. 168-212, Jun. 2016.

STAKE, R. E. The case of case study research. Thousand Oaks: Sage Publications, 1995.

VAHLNE, J. E.; JOHANSON, J. From internationalization to evolution: the uppsala model at 40 years. Journal of International Business Studies, [s.I.], v. 48, n. 9, p. 1087-1102, Dec. 2017.

VAN DE VEN, A. H. Suggestions for studing strategy process: a research note. Strategic

Management Journal, [s.I.], v. 13, n. 51, Special Issue Summer, p. 169-188, 1992.

VERNON, R. International investment and international trade in the product cycle. Quarterly Journal of Economics, [s.I.], v. 80, n. 2, p. 191-207, May 1966.

WELCH, C.; WELCH, L. S. Broadening the concept of international entrepreneurship: internationalization, networks and politics. Journal of International Entrepreneurship, [s.I.], v. 2, n. 3, p. 217-237, Sep. 2004.

ZAHRA, S. A.; GEORGE, G. International entrepreneurship: the current status of field and future research agenda. In: HITT, M. A.; IRELAND, R. D.; SEXTON, D. L.; AMP, S. M. (Eds.) Strategic entrepreneurship, creating a new mindset. Oxford, UK: Blackwell, 2002. p. 255-288.

Submetido em: $27 / 01 / 2018$

Aceito em: 08/03/2019 